\title{
Brain Reactions Caused by Administration of Antigen
}

\author{
S.V. Perekrest*, N.S. Novikova and E.A. Korneva \\ Department of General Pathology and Pathophysiology, Institute of Experimental Medicine NWB RAMS, Saint- \\ Petersburg, Russia
}

\begin{abstract}
The present review deals with the reactions taking place in the central nervous system after antigen administration. The activation of brain cells and the involvement of various neurotransmitter systems after applying various antigens are described. The possible pathways of signal transduction from immune cells to the central nervous system (CNS) are analyzed. The knowledge acquired about the activation pattern of different neuron populations could help to clarify the mechanisms of immune-to-brain communication.
\end{abstract}

Keywords: Neuro-immune interactions, antigen, hypothalamus

\section{INTRODUCTION}

The key problem of neuroimmunephysiology, a new, intensively developing biological science, is to study the central mechanisms of neuro-immune cooperation. It is necessary to elicit the mechanisms involved and search for new neural pathways and transmitters that participate in this network, and also consider the cellular, ligand-receptor and molecular mechanisms of this interaction.

On the boundary of the XIX-XX-th centuries Savchenko [1] was first to present evidence for neuroimmune interactions. He established that pigeons after transection of the cervical spinal cord become susceptible to the Siberian ulcer which normally does not cause disease in pigeons. Later on similar effect were observed after removal of cerebral hemispheres in pigeons [2]. Metalnikov [3] established that the nervous- and immune systems interact. This was the beginning of Neuroimmune Biology. Further, a set of studies in various experimental models confirmed the

${ }^{*}$ Correspondence to: S.V. Perekrest, Department of General Pathology and Pathophysiology, Institute of Experimental Medicine NWB RAMS. 197376 Acad. Pavlova str., 12. Acad. SaintPetersburg, Russia. Tel.: +7(812)2340764; Fax: +7(812)2349493; E-mail: perekrest.sv@gmail.com. interaction of the central nervous system (CNS) with the immune system. The effect of efferent pathways of CNS on immune function, and the influence of antigen introduction on the brain were investigated.

Special attention is given to the role of hypothalamus in neuro-immune interactions because of the functional features of this brain area, being the vegetative centre of functional integration of various organs and systems in the body and regulator of environmental adaptation.

\section{ACTIVATION OF NEURONS IN CNS STRUCTURES IN RESPONSE TO ANTIGENIC STIMULATION}

Broun [4] performed some early studies on the electric activity of neurons during the development of immune reactions. He observed that after immunization of rabbits with BCG vaccine and in acute tuberculosis the number of active neurons increased in the anterior and posterior hypothalamic nuclei, and decreased in the mammilary area and in the medial structures of medial hypothalamus.

Subsequently neuronal activation was shown during the first hours after immunization and later on, during the development of the immune response. 
In rabbits the posterior hypothalamic area responded to horse serum administration (as assessed by neuronal firing) within 19-30 minutes [5, 6] and remained activated for 10 days. «The second wave» of neuronal activation is observed on the 15th day of immune response which terminated by day 20-30. Similarly, the firing of ventromedial hypothalamic nuclei (VMH) increased several times after sheep erythrocytes administration that correlated in time with maximum antibody titre in blood. In other hypothalamic structures, such as the (arcuate; Arc), and paraventricular nucleus (PVN), and also preoptic, anterior $(\mathrm{ANH})$ and posterior hypothalamic $(\mathrm{PH})$ area correlation was not observed [7]. Maximal reaction was shown during immunogenesis in the $\mathrm{PH}$ and preoptic hypothalamic area on the first day of immune challenge, which shifted to periods of suppression on the eighth day after antigen administration [8]. The study of slow potentials in locus coeruleus (LC) during 24 hours after intravenous injection of sheep erythrocytes revealed an individual character of reaction. Most animals showed a 2-wave dynamics with positive peaks on days 2-3 and 8-9 days after antigen injection [9]. In $\mathrm{PH}$ there was an alteration in slow potentials at 2 hours and on the 1 st and the 5th day after immunization [10, 11]. Besides, within 30 minutes after sheep erythrocytes injection the shift of hypothalamic biogenic amines and their balance was observed [12].

A modern approach for studying neuro-immune interactions is to examine the influence of mediators produced during immune reactions on neuronal activation in various brain structures. Intravenous or intraperitoneal lipopolysaccharide (LPS) injections are often applied for this purpose.

A number of studies showed activation of various brain structures using c-Fos protein expression. The hypothalamus was activated after various stimuli, including antigen injection [13-15]. The results show that the intensity, localization and duration of c-fos gene expression in the CNS depend on the character and the pathway of administration of the stimulus.

LPS or IL-1 injection leads to activation of noradrenergic neurons of hypothalamus, and intravenous or intracerebroventricular injection of IL-1 causes increase of c-fos mRNA and c-Fos protein expression in cells of PVH, Arc and supraoptic hypothalamic nucleus (SO) [16-18]. In addition the administration of antigens (tetanus anatoxin, LPS), leads to cell activation in hypothalamic structures which are more significant in $\mathrm{AHN}, \mathrm{PVH}, \mathrm{PH}$ and lateral hypothalamic area (LHA) [19-22]. Concentration of injected antigen, in turn, influences the pattern of hypothala- mic structure activation. After administration of low dose of LPS $(25 \mathrm{mg} / \mathrm{kg})$ the greatest quantity of activated neurons is observed in PVH, AHN, PH, LHA [23] while the injection of a subseptic dose $(500 \mathrm{mg} / \mathrm{kg})$ involves more significant activation in $\mathrm{PVH}, \mathrm{AHN}$ and to a lesser degree in LHA (Fig. 1) (Perekrest S.V., unpublished data).

Ranking of the activated cells in this area according to their sizes allows for the characterization of activation pattern in LHA after injection of various LPS doses. This is important for studying the mechanisms of regulating signal formation and transfer from neurons activated after antigenic stimulation. After injection of lower LPS dose neurons of the associative type $\left(10-50 \mu \mathrm{m}^{2)}\right.$ are mainly activated, e.g. the signal from neurons that received the information can mainly be transducted to cells within activated structure [24]. Administration of a higher dose of LPS $(500 \mathrm{mg} / \mathrm{kg}$ ) except activation of associative neurons leads to activation of relay neurons $\left(70-150 \mu \mathrm{m}^{2}\right)$ that causes signal transmission to other brain structures and formation of the systemic response, characteristic for reaction to LPS injection (Fig. 2) [Perekrest S.V., unpublished data].

In conclusion, LPS injection causes neuronal activation in brain structures participating in regulation of food uptake (the central nuclei of amygdala, basolateral amygdala, and LHA) [25], sleep/wake cycle (tuberomammilary nucleus) [26], and activation of the hypothalamo-pituitary-adrenal (HPA) axis (PVH) [27].

Unlike reactions to LPS injection, a $\mathrm{T}$ celldependent antigen, staphylococcal enterotoxin B (SEB), causes a different pattern of c-Fos protein expression, mainly in the solitary tract and central amygdala nuclei, the cellular response of PVH being mild [21, 27].

After bovine serum albumin (BSA) injection, (another T cell-dependent antigen), the highest degree of activation was observed in PH and LHA. Smaller quantity of c-Fos-positive cells was present when compared with LPS administration. Better results were obtained when c-fos gene expression was observed by the increase in optical density (Fig. 1) [23].

It is clear that antigen application leads to the activation of the certain CNS structures and its pattern depends on the nature and doses of injected antigen, which indicates the «specificity» of CNS reactions to antigenic stimulation. One may suggest that the difference of these reactions is caused by different kind of information coming to the brain after stimulation by different antigens. 
A

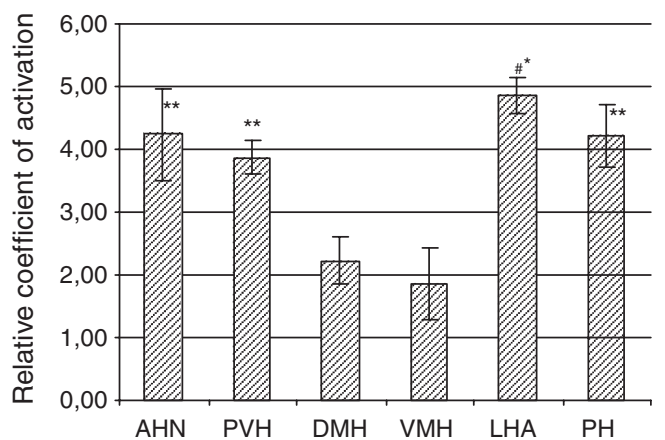

C

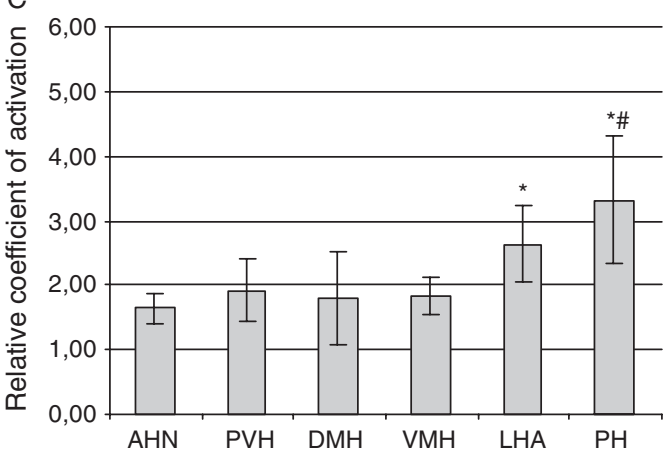

B

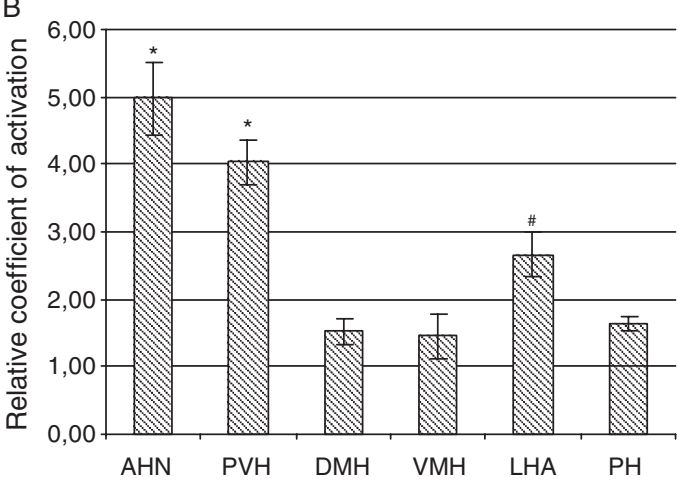

D

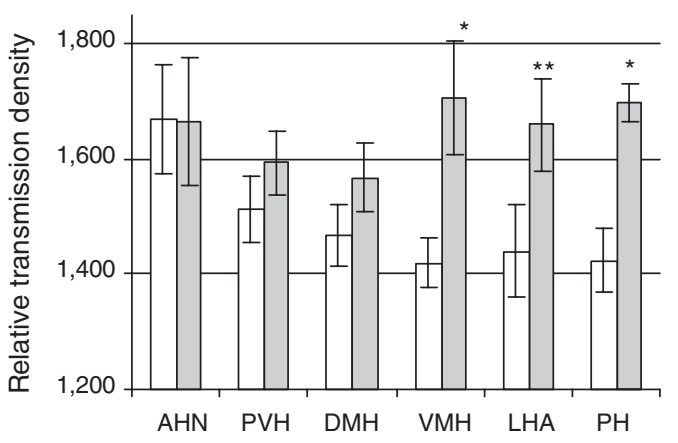

Fig. 1. Relative coefficient of activation and relative transmission density of cells in different hypothalamic structures after antigen injection. Injection of: Lipopolysaccharide. A - $25 \mathrm{mg} / \mathrm{kg}(\mathbb{Z})$ ) * -F $P<0.01$, ** $-P<0.05$ compared to RCA in VMH and DMH; \# - $P<0.05$ compared to RCA in PVH; B - $500 \mathrm{mg} / \mathrm{kg}(\mathbb{B})$; * - $P<0.01$ compared to RCA in VMH, DMH, LHA and PH; \# - $P<0.05$ compared to RCA in VMH, $\mathrm{DMH}$, and PH; Bovine serum albumin $(25 \mathrm{mg} / \mathrm{kg})$. C - relative coefficient of activation: $*-P<0.05$ compared to RCA in AHN; \# - $P<0.05$ compared to RCA in VMH. D -relative transmission density: $\square$ - saline injection; $\square$ - BSA injection; $*$ - $P<0.01$, ** $-P<0.05$ compared to RTD in animals injected with saline. The comparison of hypothalamic structures activation is carried on by relative coefficient of activation (RCA, calculated as the ratio of c-Fos-positive cells number with antigen/saline) and by relative transmission density (RTD, calculated as the ratio of cell transmission density / background).

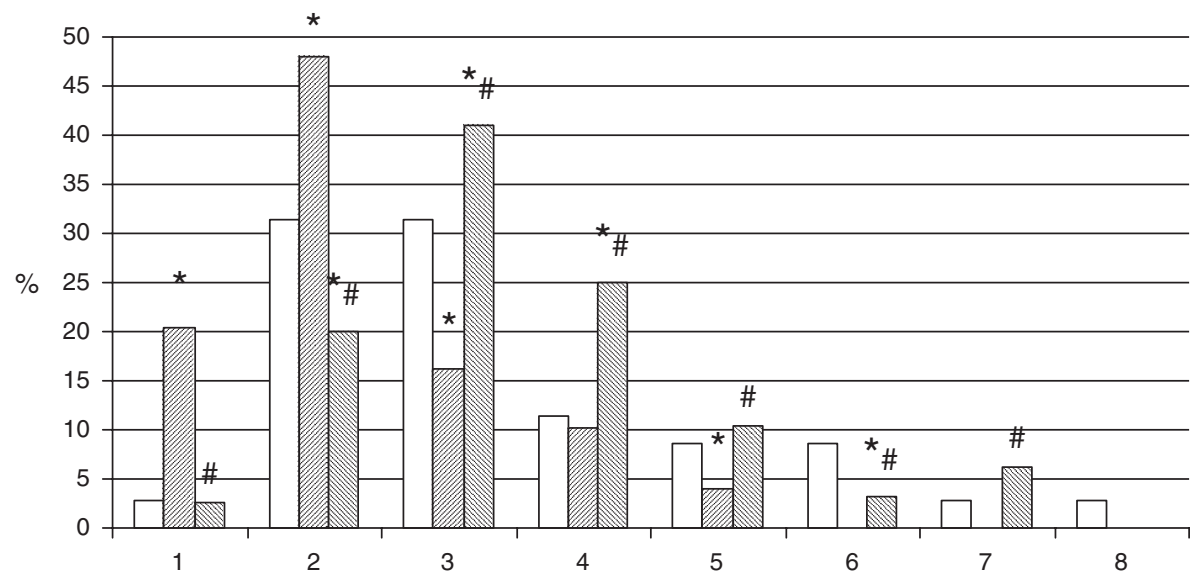

Fig. 2. The quantity of c-Fos-positive cells in LHA of different sizes. $\square$ - saline injection, $\mathbb{Z}$ - LPS injection (25 mg/kg), $\mathbb{Q}$ - LPS injection $(500 \mathrm{mg} / \mathrm{kg})$. Cell ranks: $1-10-30 \mu \mathrm{m}^{2} 2-31-50 \mu \mathrm{m}^{2}, 3-51-70 \mu \mathrm{m}^{2}, 4-71-90 \mu \mathrm{m}^{2}, 5-91-110 \mu \mathrm{m}^{2}, 6-111-130 \mu \mathrm{m}^{2}, 7-$ $131-150 \mu \mathrm{m}^{2}, 8-151-170 \mu \mathrm{m}^{2}$. $*-P<0,05$ compared to the quantity of c-Fos-positive cells after saline injection; \# - $P<0,05$ compared to the quantity of c-Fos-positive cells after LPS $(25 \mathrm{mg} / \mathrm{kg})$ injection. 


\section{PARTICIPATION OF VARIOUS NEUROTRANSMITTER SYSTEMS IN CNS REACTIONS TO ANTIGENS}

Infectious process and inflammation influence many behavioural functions, including food intake, social behaviour, sleep/wake cycle, etc. The mechanisms underlying the development of so-called "sickness behavior" remain only partially clarified. This is an important problem of immunophysiology. It is known that increasing concentrations of circulating cytokines in reply to an antigen lead to development of various reactions: anorexia, drowsiness, fever, and activation of the HPA axis. Intravenous injection of IL-1 leads to development of the above listed reactions [28]. The IL-1 involved is synthesized in the brain [29]. The application of specific antagonists of proinflammatory cytokines reduce systemic reactions caused by LPS [30]. Antigen administration leads to activation of many CNS structures which influence the sleep/wake cycle, food intake, water-salt metabolism, stress reactions etc.

\section{The effect of antigen injection on noradrenergic neurons}

CNS reactions to antigen stimulus involve the activation of different neurons affiliating with the noradrenergic system which are involved in multiple ascending neural pathways including catecholaminergic "danger" pathways [31]. Activation of noradrenergic neurons within the nucleus of the solitary tract and caudal ventrolateral medulla that inervate PVH is necessary for a full HPA axis response to systemic immune challenge $[32,33]$. Noradrenaline stimulates in the PVH corticotropin-releasing factor (CRF) gene expression, which leads to activation of the HPA axis [34].

At the same time LPS or IL-1 injection leads to the activation of noradrenergic neurons in hypothalamus. Intravenous or i.c.v. injection of IL-1 stimulates the increase of neuronal firing and c-fos expression in PVH, Arc and SO [16-18]. Intravenous introduction of LPS or IL-1 to animals leads to an increase in cFos-protein expression in sympathetic preganglionic neurons, and also to higher release of catecholamines from the splenic nerve terminals $[22,35,36]$. The reactions of catecholaminergic neurons to antigen injection are often considered in connection with the influence of antigen stimulus (or effects of cytokines, in particular, IL-1), as mediators of the immune system, produced in response to antigen injection) on HPA axis.
Intraperitoneal (i.p.) and intracerebroventricular (i.c.v.) injection of IL-1, as well as in vitro application, stimulates production of CRF in hypothalamic cells [37]. The effects of IL-1 on HPA axis are mediated by its influence on catecholaminergic neurons producing CRF. Stimulation of HPA axis by IL-1 is blocked after transection of noradrenergic fibers that end on CRFproducing neurons in $\mathrm{PVH}$ as well as after noradrenalin antagonist injection [38-41]. Besides, LPS injection stimulates NO production in PVH that facilitates HPA axis activation [42], the transcription of CRF receptor being increased in this structure [43]. IL-6 and TNF- $\alpha$ possess the same effects as IL-1 [44-46].

More recently it was shown that repeated injection of antigen (within 6 days) doesn't lead to reactions mentioned above. Apparently desensitization takes place, HPA activation is blocked and anorexia develops [47]. Intraperitoneal (i.p.) LPS injection is known to cause a significant increase in norepinephrine turnover in LC of mice [48] - this represents a part of a neuronal network that is specifically activated by prostaglandin E2 to increase thermogenesis and produce fever [49]. Besides, nitric oxide in LC has been reported to be a mediator of LPS-induced fever. Inhibition of NOsynthase in rat LC delays hyperthermia caused by LPS injection [50, 51]. Furthermore, LPS was shown to activate $\alpha$-adrenergic receptors and stimulate norepinephrine release in the hypothalamic preoptic area, which caused the lowering of arterial pressure and could be a possible mechanism of endotoxic hypotension [52].

\section{Cholinergic neurons after antigen injection}

The studies of cholinergic neuron reaction to immune challenge are focused on the activation of vagal afferent fibers, ganglions and dorsal vagal complex cells after antigen injection. The involvement of vagus system will be discussed in more detail in the part "Possible pathways of neuronal signal transmission from immune system to brain".

\section{Serotoninergic neurons after antigen injection}

There are less and controversial data about reactions of serotoninergic neurons to antigen. The application of serotonin antagonist was shown to abolish anorexia in rats cuased by LPS injection. The LPS-induced activation of raphe nuclei, central amygdala, nucleus of solitary tract and PVH was also significantly decreased [53]. Evidently, serotonin caused activation of neuronal networks responsible for anorexia. Further, the 
application of various serotonin antagonists had no effect on hypophagia in mice after i.p. IL-1 or LPS injection [54]. This could lead to conclusion that serotonin doesn't participate in food intake regulation and sickness behaviour. Besides, after intranigral or i.p. LPS injections serotonin and dopamine turnover in the midbrain, striatum and frontal cortex was increased, and locomotor function was elevated $[55,56]$.

\section{Dopaminergic neurons after antigen injection}

The effect of LPS injections on reactions of dopamine neurons is often used as a model for Parkinson's disease $[55,57,58]$. For this purpose the antigen is injected intranigral or intrastriatal. In both cases neurodegenerative processes of dopaminergic neurons are observed in substantia nigra as the result of inflammation. LPS injection leads to decrease of dopaminergic neuron quantity at the ipsilateral side but increase at the contralateral side [55, 57]. Development of neurodegenerative processes in this model possibly is caused by the activation of NO production by glial cells that inhibits the respiration of neurons in culture and stimulates glutamate release by such neurons [59].

Intaperitoneal administration of LPS also affected the dopaminergic system. Within 4 hours after injection, the concentrations of dopamine and its metabolites were significantly increased in the anterior olfactory nucleus, although no changes were revealed in cells of the olfactory bulbs $[60,61]$.

\section{Neuropeptide Y containing neurons after antigen injection}

Since LPS injection influences various behavioural reactions, including food uptake, it is very important to study neuropeptide Y (NPY) neurons in order to understand the mechanisms of sickness behaviour. Recent studies reported that NPY-neurons are involved in the CNS response to antigen. Within 2 hours after i.p. injection of LPS $(500 \mathrm{mg} / \mathrm{kg})$ NPY expression was decreased in the hypothalamus. Simultaneously a decrease in food intake lasting 24 hours was observed. The additional administration of NPY prevented the development of anorexia [62]. The authors suggest that the alterations in NPY synthesis after LPS injection was probably mediated by insulin since insulin deficient rats show no disturbances in food intake after LPS injection. Insulin injections to such rats restore the LPS-induced anorexia.

Other experiments showed that single or repeated administration of LPS $(100 \mathrm{mg} / \mathrm{kg})$ for 6 days caused no changes in expression of NPY and proopiomelanocortin (POMC) mRNA in neurons of Arc, however, the appetite of treated animals was decreased [47]. This contradiction may result from low dose of an antigen. Reactions to higher doses are more pronounced and can involve other mechanisms and pathways of signal transmission in the CNS. It was also shown that IL-1 injection caused c-fos gene expression in neurons of Arc, which contains both POMC and NPY, and participates in the regulation of feeding behaviour [63]. The authors suggest that neurons in the Arc are more likely to be involved in the correction of abnormal feeding function, than in the prevention of anorexia development.

Investigations in NPY receptor knockout mice showed that endogenous NPY must combine with its receptor, Y2, in order to enable the CNS to react with antigen. In these knockout mice body temperature and corticosteron elevation in blood are less exspressed after LPS injection compared to wild type animals. Y2 knockout mice are more susceptible to LPS induced behavioural reactions (e.g. anxiety, decrease in locomotor function and social behaviour) [64].

\section{Vasopressin-containing neurons after antigen injection}

LPS injection reduces diuresis and raises vasopressin level in blood. LPS activates neurons in SO, as revealed by their electric activity and by c-Fos protein mRNA expression, which begins at 30 minutes and lasts more than 6 hours [65]. There is also an increase of IL-6 mRNA in these neurons. The same effect is observed after i.c.v. injection of IL-6. The administration of antibodies to IL-6 abolished the LPS-induced activation of vasopressin-containing neurons in SO. This provides evidence that IL- 6 activates vasopressin containing neurons in SO.

Priming with LPS i.p. strengthens the reaction of vasopressin-containing neurons to hypertensive saline injection. The enlargement of the axonal varicosities containing vasopressin was shown at 3 hours after LPS injection. The subsequent injection of hypertensive saline leads to considerable decrease in vasopressin-immunoreactivity of axonal varicosities in neurohypophysis and IL-1 $\beta$ and IL-6 synthesis is induced in the posterior lobe of the pituitary gland [66]. Furthermore a discrete reaction of PVH cells is observed. Despite a lowered vasopressin mRNA in neurons in 6 hours after LPS injection, transcription of vasopressin in magnocellular $\mathrm{PVH}$ remained unchanged. However, in parvocellular PVH 
the increase in vasopressin transcription was observed after LPS administration and then after hypertensive saline injection [66]. One should note that the effects of LPS on neuron activation in the PVH and SO are dose-dependent $[67,68]$.

On the one hand, injection of both low and high doses of LPS leads to increase of c-Fos-immunoreactivity in vasopressin- and oxytocin-containing neurons in PVH, SO and nucleus circularis (NC). Furthermore, the activation of magnocellular $\mathrm{PVH}$ is heterogeneous (the relative quantity of c-Fos-positive cells in SO is considerably higher, than in PVH and NC). Parvocellular PVH also revealed high level of activation. Possibly due to the activation of magnocellular SO, PVH and NC the LPS-induced increase in peripheral secretion of vasopressin and oxytocin [69].

On the other hand, the application of an $\alpha 1$ adrenoreceptor antagonist suppresses the LPS-induced activation of neurons in PVH and SO only after injection of low doses of LPS [68]. Cycloxygenase inhibitor indomethacin blocks expression of c-fos gene in PVH, SO and LC also at low doses of LPS, at higher doses this effect is not observed [67]. These findings suggest that the effects of LPS on activation of vasopressin-containing neurons most likely are mediated by norepinephrine and prostaglandins.

\section{Histaminergic neurons after antigen injection}

Histaminergic neurons localized in tuberomammilary hypothalamic nucleus are known to participate in regulation of such physiological functions as thermoregulation, awakening, maintenance of energy balance, memory and training, which can be altered after administration of antigens. LPS or IL-1 injection leads to an increase in histamine turnover in the rat hypothalamus, and histamine itself has inhibitory effect on LPS- and IL-1-induced fever, but facilitates anorexia. TNF- $\alpha$ appears not to be involved in histaminergic pathways [70].

The effect of LPS injection on histaminergic neurons of tuberomammilary hypothalamic nucleus is mediated by the activation of catecholaminergic neurons of the dorsal vagal complex since its inactivation by local anesthetics leads to decrease in histaminergic activation [71]. Vanadil-sulphate injection was shown to block the neuro-immune interactions at the level of vagal afferents that abolishes LPS-induced sickness behaviour [72]. The investigation of histaminergic neurons of tuberomammilary area revealed an increase in their activation in rats after LPS injection during the dark period [73].
The concentrations of histamine and its metabolites in hypothalamus are increased 15 minutes after LPS administration as indicated by the intensification of histamine turnover in neurons $[74,75]$. The application of histamine receptor antagonists inhibits the secretion of ACTH, $\beta$-endorphin and prolactin, which was caused by LPS injection. This indicates that histaminergic neurons are involved of in the regulation of systemic response to antigen [74-76].

\section{Orexinergic neurons after antigen injection}

Many studies on orexin (ORX) since its discovery in 1998 have revealed that ORX participates in regulation of many vegetative functions (e.g. feeding behaviour, sleep/wake cycle, thermoregulation, pain perception, stress). Of the particular interest is the possible involving of orexin-containing neurons localised in LHA in CNS reactions and in the systemic response to antigen stimulus.

The activation of orexin-containing neurons (assessed by c-Fos protein) caused by exploratory behaviour in rats was considerably decreases after LPS injection. At the same time LPS administration leads to increase in c-Fos-positive orexin-containing neurons at daytime [73]. On the contrary, at night, when animals are active, LPS injection led to decrease in activation of orexin-containing neurons that coincided with some manifestations of sickness behaviour.

Mice, fed after 12 hours of starvation, and 6 hours after LPS injection demonstrated a decrease of c-Fos gene expression in orexin-positive neurons of LHA that correlated with the lowered food intake [77]. Orexin-containing neurons change after LPS injection, which leads to alterations of their immunoreactivity demonstrated immunohistochemically in hypothalamic structures on brain slices. The dynamics of these changes is dose-dependent. The administration of $500 \mathrm{mg} / \mathrm{kg}$ body weight of LPS leads to decrease in quantity of orexin-positive neurons only after 6 hours of injection (Fig. 3) [78]. This dose is rather high and may be characterized as subseptic [79]. LPS administration in a dose of $25 \mathrm{mg} / \mathrm{kg}$ causes an increase in quantity of orexin-positive neurons 2 and 4 hours after injection (Fig. 4) [80]. The increase or decrease of orexin content in neurons indicates a shift in balance between synthesis and utilization of this neuropeptide e.g. immunohistochemically revealed alterations may result from the prevalence of one of these processes over another.

Within 2 hours after the administration of both $25 \mathrm{mg} / \mathrm{kg}$ and $500 \mathrm{mg} / \mathrm{kg}$ of LPS, an increase in pre- 

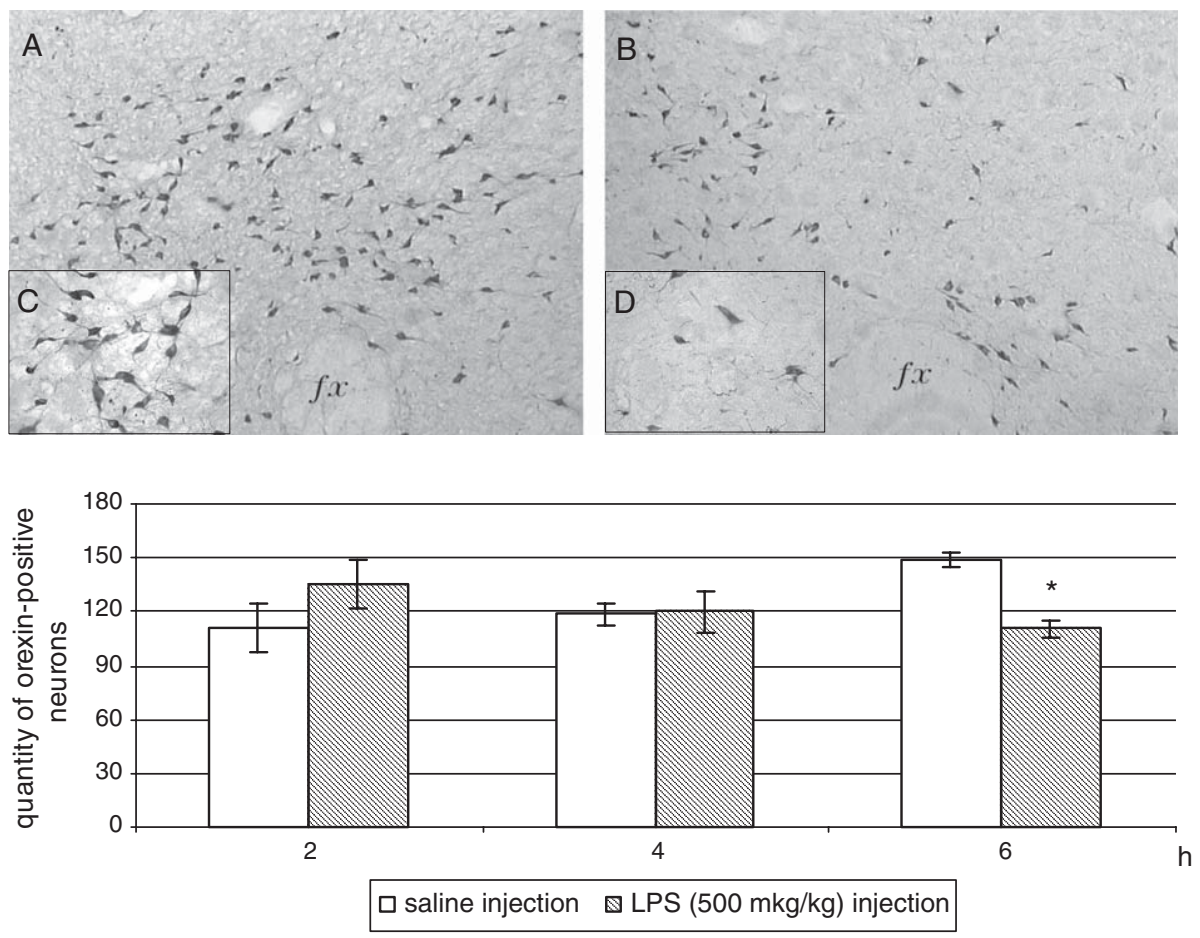

Fig. 3. Orexin-positive neurons after LPS injection. A, B, C, D - microphotographs of orexin-containing neurons in LHA in 6 hours after saline $(\mathrm{A}, \mathrm{C})$ or LPS $500 \mathrm{mg} / \mathrm{kg}$ (B, D) injection. A, B $-\times 10$ magnification. C, D $-\times 40$ magnification. E - the quantity of orexin-positive neurons in $2,4,6$ hours after saline or LPS injection. $*-P<0,05$ compared to the quantity of orexin-positive neurons after saline injection.

proorexin gene expression in hypothalamic cells was shown, which was indicated by a quantitative increase of preproorexin mRNA. There were no changes at 4 and 6 hours (Fig. 5) (Perekrest S.V. et al., unpublished data). It may be concluded that Orexin-containing neurons react differently to different doses of LPS. In all cases preproorexin was increased, but orexin utilization after a subseptic dose of LPS was more intensive, shifting balance of orexin synthesis and consumption towards increased utilization.

LPS, which is a T cell-independent antigen with high immunogenicity, is often used to study neuro-immune interactions. The effects of T cell-dependent antigens (SEB, BSA) on the activation of various CNS structures are different from those of $\mathrm{T}$ cell-independent antigens $[21,23]$. The T cell-dependent antigen, BSA, induces a similar reaction of orexin-containing neurons to small doses of LPS (Abramova T.V. et al, unpublished data), e.g. orexin-positive neurons are increased within 2 and 4 hours after antigen injection (Fig. 6). LPS stimulates innate immunity whereas BSA induces an antibody response. The central effects of BSA, which is a weak antigen, are comparable with the dynamics of small LPS doses. These data indicate that orexin-containing neurons participate in neuro-immune interactions during the inductive phase of immune reactions. It may be concluded that orexincontaining neurons are important for the development of immune reactions and may play a role also in the development of sickness behavior.

Various neurotransmitter systems are involved in the reaction of CNS to antigen, which lead to the formation of various pathways of systemic responses that affect the regulation of various vegetative functions.

\section{POSSIBLE PATHWAYS OF NEURONAL SIGNAL TRANSDUCTION FROM IMMUNE SYSTEM TO THE BRAIN}

It is important to study the pathways of signal transmission from the immune system to the CNS, and examine the various patterns of activation and the intensity of afferent signals. These are important aspects of neuro-immune interactions. To date most investigators studied the afferent fibers of the vagus nerve for transmission of antigenic/inflammatory signals to the CNS.

It was discovered in 1994 [35] that the induction of c-Fos-protein synthesis in cells of PVH and SO in 

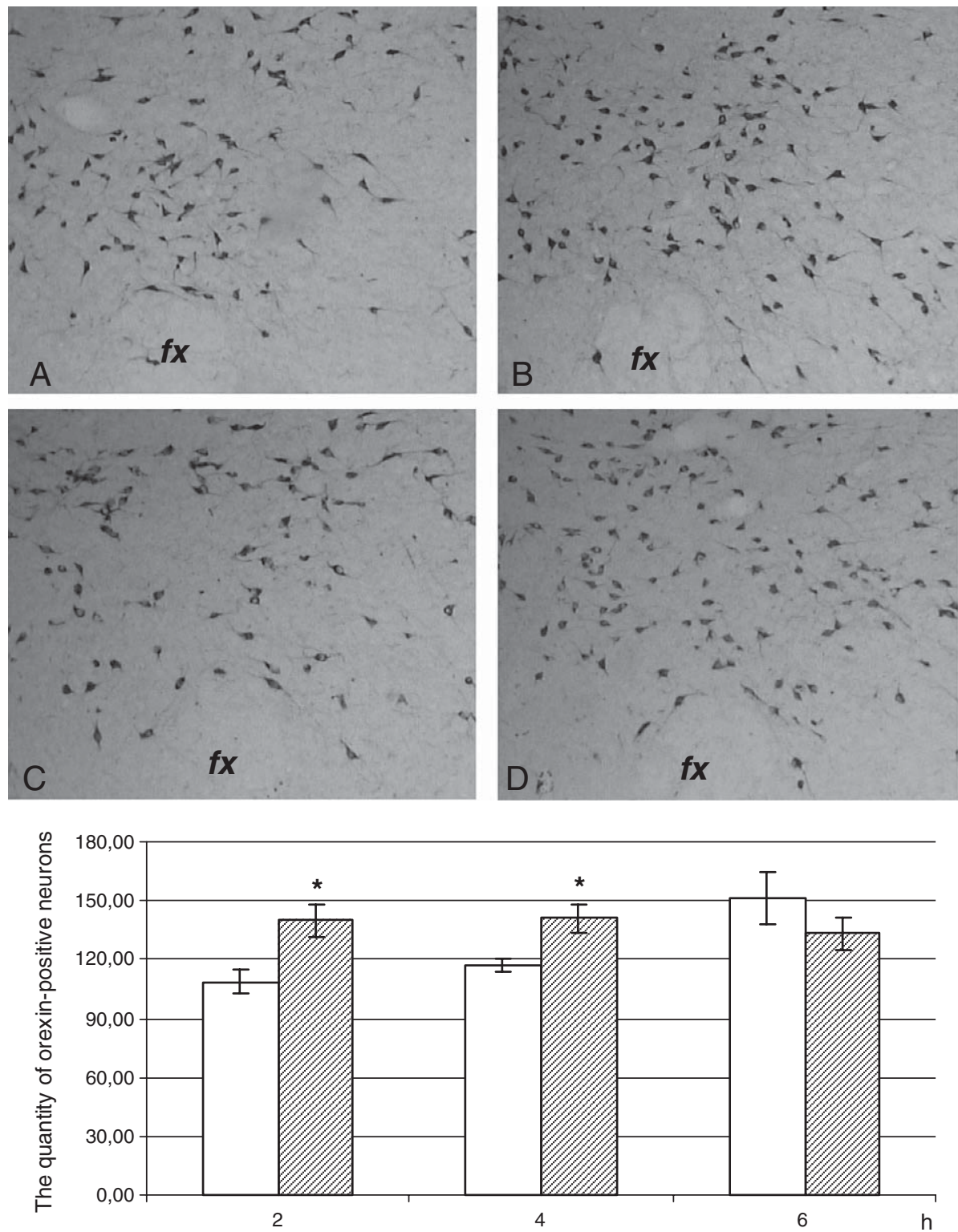

Fig. 4. Orexin-positive neurons after LPS injection. A, B, C, D - microphotographs of orexin-containing neurons in LHA in 2 (A, B) and 4 (C, D) hours after saline (A, C) or LPS (B, D) injection. $\times 10$ magnification. E - the quantity of orexin-positive neurons in 2, 4, 6 hours after saline $(\square)$ or LPS $25 \mathrm{mg} / \mathrm{kg}(\mathbb{Z})$ injection. * $-P<0,05$ compared to the quantity of orexin-positive neurons after saline injection.

response to i.p. injection LPS was blocked by subdiafragmatic transection of the vagus nerve. Also it has been shown that subdiafragmatic vagotomy attenuated the sickness behaviour, which was caused by i.p. injection of LPS [81], the typical hyperalgesia and hyperthermia were also abolished [82, 83], but LPS-induced cytokines production in various organs, including the CNS, as well as their blood level did not change [81, 84-86]. One may conclude that intact vagus nerve is necessary for the formation of adequate
CNS response to the intraperitoneal administration of LPS. It is very likely that the subdiafragmatic afferent fibers of vagus nerve do not participate in the development of the LPS-induced anorexia [87].

The plasma levels of ACTH and corticosterone are unchanged in vagotomized animals after i.p. injection of TNF- $\alpha$ [88]. Similarly IL-1 injection to vagotomized animals leads to increase in ACTH and corticosterone levels in serum, but to a lesser degree, than in animals with intact vagus nerve $[89,90]$. The effects of 


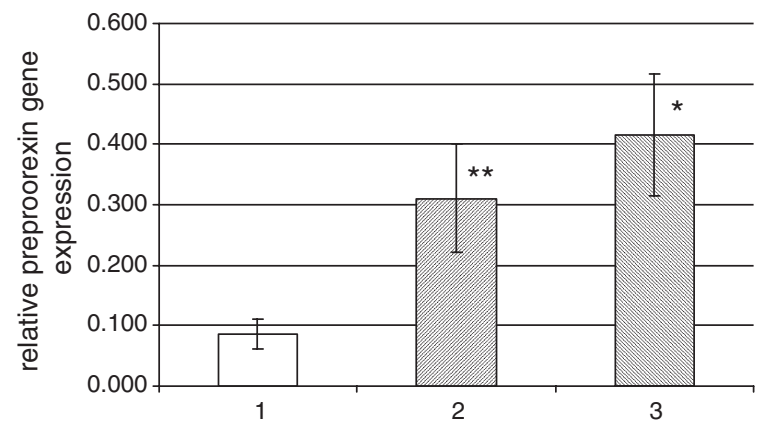

Fig. 5. Expression of prepro-orexin gene in hypothalamic cells in 2 hours after LPS injection. Injections: 1 - saline, 2 - LPS $(25 \mathrm{mkg} / \mathrm{kg})$, 3 - LPS $(500 \mathrm{mkg} / \mathrm{kg}), *-P<0,01, * *-P<0,05$ comparing to prepro-orexin gene expression after saline injection.

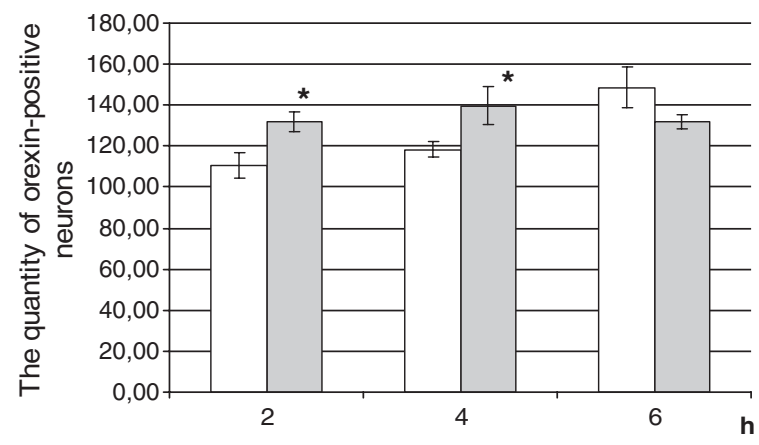

Fig. 6. The quantity of orexin-positive neurons in hypothalamic structures after BSA injection Injections: $\square$ - saline $\square$ - BSA $(25 \mathrm{mg} / \mathrm{kg}) ;{ }^{*}-P<0,05$ comparing to the quantity of orexin-positive neurons after saline injection.

i.p. LPS injections on body temperature after vagotomy are dose-dependent. Subdiafragmatic vagotomy had no influence on fever development at high dose of LPS $(1000 \mathrm{mg} / \mathrm{kg})$ [91]. It should be mentioned that vagotomy is less effective to elicit LPS- and IL-1induced CNS reactions in mice than in rats [92]. The partial blockade of signal transmission after vagotomy could be explained by the direct action of IL-1 and IL-6 on CNS cells in the area postrema and organum vasculosum lamina terminalis (OVLT) $[93,94]$.

The data on dendritic cell (DC) localization between vagal fibers and in area postrema are of particular interest $[14,95]$. The presence of a wide spectrum of receptors on DC membrane and the ability to synthesize proinflammatory cytokines in response to antigen administration can play a key role for transmission of signals from immune system to CNS. Afferent vagal fiber terminals located near DC express receptors to various mediators of immune system [96]. Intraperitoneal LPS injection increases the quantity of peritoneal macrophages in the connective tissue near vagal terminals, and leads to the increase of c-Fosimmunoreactivity and expression of IL-1 R mRNA in neurons of nodose ganglion of vagus [97]. Later TLR4 and its mRNA have been revealed in these cells that presumably create a basis for activation of vagal afferent fibers at the level of nodose ganglion and can explain the maintenance of CNS reactions to LPS injection after subdiafragmatic vagotomy [98]. I.v. or i.p. administration of IL-1 or LPS as well as SEB causes c-Fos-protein expression in sensitive neurons of parasympathetic ganglions [99, 100]. Using fluorogold for retrograde transport Goehler et al. [14] have revealed innervation of certain lymph nodes from the jugular and nodose ganglion of vagus nerve.

Vagal afferent fibers are known to reach medulla oblongata terminating in dorsal vagal complex, including the area postrema, a nucleus of solitary tract and dorsal nucleus of $n$. vagus. In a number of works it was shown that there is an increase of c-Fos-protein expression in all the above mentioned structures 2 hours after LPS injection [20, 101-105]. The activation of higher CNS structures is also observed in the PVH, structures of amygdala, and of thalamic nuclei. Three possible targets have been suggested for increase of cytokine level through n.vagus: $\mathrm{PVH}$, thalamic nuclei and amygdala [14].

An additional pathway of signal transduction from the immune system to catecholaminergic neurons in the medullary visceral zone and to central amygdala nuclei through vagal fibers was observed using a triplelabeling immunohistochemical method. An increase in c-Fos-immunoreactivity in neurons of medullary visceral zone and in central amygdala nuclei was revealed after i.p. LPS injection. Subdiafragmatic vagotomy decreased the quantity of c-Fos-positive cells in these structures [106]. The authors suggested that the catecholaminergic neurons in the medullary visceral zone serve as a neural relay station in the immune-tobrain communication, transmitting information from $\mathrm{n}$. vagus to central amygdala nuclei.

When the dorsal vagal complex was inactivated with local anesthetics, neuronal activation in the central amygdala nuclei, lamina terminalis, PVH and ventromedial preoptic area was considerably decreased 2 hours after i.p. LPS injection. The effects LPS on animal behavior was completely abolished, which serves as evidence for the involvement of dorsal vagal complex in antigen mediated signaling of the neural structures that modulate social behaviour [107].

Pathways of afferent signal transmission in bacterial infections are closer to reality than LPS injection 
and are of particular interest. Oral inoculation with Compylobacter jejuni leads to substantial increase in c-fos gene expression in neurons of visceral sensory nuclei in the brainstem (the nucleus of the solitary tract and the lateral parabrachial nucleus) and PVH in one and two days after the challenge $[108,109]$. The level of circulating proinflammatory cytokines (TNF$\alpha$, IL-1 $\beta$, IL-6) in blood did not change. Research of animal behaviour has revealed enhanced anxiety-like behavior in infected mice [110]. This reaction, possibly, is mediated by the activation of neurons in PVH, basolateral nuclei of the amygdala, bed nucleus of the stria terminalis and medial prefrontal cortex. In control animals, which instead of $C$. jejuni received saline, anxiety-like behavior in holeboard was mediated by activation of neurons in central and basolateral nuclei of the amygdala.

These results deal with one pathway of information transmission from the immune system to the CNS. The existence of other pathways for this kind information transmission cannot be excluded and requires further research. It should be stressed that the data mentioned above about the specificity of the pattern of activation of hypothalamic structures after injection of different antigens are consistent with the observations in different systems when the antigen is coming to the brain after application through nervous or humoral pathways.

\section{CONCLUSIONS}

Numerous observations indicate that antigenic stimulation elicits a response in the CNS. Many studies reported the activation of brain structures (mainly hypothalamic) after antigen administration. The pattern elicited depends on the nature, dose and intervals of antigen injection. It appears that different antigens generate specific signals that elicit in the nervous system, and produce specific responses that correspond to the received information. CNS reactions to different antigens involve different neurotransmitter systems that participate in the regulation of various physiological processes, and the involvement of neurons with different neurotransmitters creates a basis for the formation of a systemic response to the applied antigen. The pathways of transmission of information from immune to nervous system partly clarify the mechanisms of neuroimmune interactions after antigen application. Taken together these results could serve as the foundation of CNS reactions to immune challenge.

\section{REFERENCES}

[1] Savchenko IG. To a question on immunity to the Siberian ulcer. The Doctor. 1891; (5): 132. [in Russian].

[2] London ES. About influence of removal of various parts of a brain on immunity of the Siberian ulcer. Arh. Biol. Sciences. 1899; 7: 177. [in Russian].

[3] Metalnikov S. Role du système nerveux et des facteurs biologiques et psychiques dans l'immunité. Ann. Inst. Pasteur. Paris. 1926; 40: 893.

[4] Broun GR, Mogutov SS, Caen GS. The role of some hypothalamic structures in regulation of immunobiological processes after immunisation with BCG vaccine. Bull. of experim. biol. and med. 1970; 70(7): 74. [in Russian].

[5] Klimenko VM, Kaplunovsky AS. Statistical research of pulse activity of posterior hypothalamic structures. Physiol. Journ the USSR. 1972; 58(10): 1484. [in Russian].

[6] Korneva EA, Klimenko VM, Shhinek EK. Neurohormonal maintenance of immune homeostasis. Leningrad: Science; 1978. [in Russian].

[7] Besedovsky HO, Sorkin E, Felix D, Haas H. Hypothalamic changes during the immune response. Eur. J. immunol. 1977; 7: 323.

[8] Klimenko VM. Investigation of alterations of excitability of hypothalamic and limbic structures during immune reactions. In: Korneva EA, editor. Immunophysiology. Saint-Petersburg: Science; 1993. p. 129. [in Russian].

[9] Nevidimov MG, Klimenko VM. Investigation of reaction of catecholaminergic system of the brain to antigen. Stress and immunity: Proc. Of All-Union conference. Rostov-naDonu. 1989; 33. [in Russian].

[10] Grigoriev VA. Dynamic of slow potential of rabbit hypothalamic structures at early terms of immune reaction development. Physiol. Journ. USSR. 1981; 67(3): 463. [in Russian].

[11] Stolyarov ID, Grigoriev VA. Dynamic of slow potential in hypothalamic structures after tolerogen and immunogen injection. Physiol. Journ. USSR. 1985; 71(6): 694. [in Russian].

[12] Lesnikov VA, Kanichka B, Fekete M. The level of cateholamines in hypothalamus and hormonal reactions in rats at early terms after immunization. Neuro-humoral regulation of immune homeostasis: Proc. of All-Union. Simposium. Leningrad. 1986; 47. [in Russian].

[13] Kovacs KJ. Invited review c-Fos as a transcription factor: a stressful (re) view from a functional map. Neurochem. Int. 1998; 33: 287.

[14] Goehler LE, Gaykema RP, Hansen MK. Vagal immuneto-brain communication: a visceral chemosensory pathway. Autonomic Neuroscience: Basic and clinical. 2000; 85: 49.

[15] Barabanova SV, Golovko OI, Kazakova TB, Korneva EA, Novikova NS, Nosov MA. Stress effectson expression of inducible genes c-fos and IL-2 in cells of nervous and immune systems. Neurochemistry. 1998; 15(4): 380. [in Russian].

[16] Rivest S, Torres G, Rivier C. Differential-effects of central and peripheral injection of interleukin-1-beta on brain c-fos expression and neuroendocrine function. Brain res. 1992; 587(1): 13.

[17] Chang SL, Ren T, Zadina JE. Interleukin-1 activation of FOS proto-oncogene protein in the rat hypothalamus. Brain Res. 1993; 617: 123.

[18] Ericsson A, Kovacs KJ, Sawchenko PE. A functional anatomical analysis of central pathways subserving the 
effects of Interleukin-1 on stress-related neuroendocrine neurons. J Neurosci. 1994; 14: 897.

[19] Nosov MA, Barabanova SV, Kazakova TB, Korneva EA. Activation of hypothalamic cells after antigen influence (by c-fos gene expression). Physiol. J. 2001; (3): 331. [in Russian].

[20] Elmquist JK, Scammell TE, Jacobson CD, Saper CB. Distrubution of Fos-like immunoreactivity in the rat brain following intravenous lipopolysaccharide administration. J. of Comp. Neurol. 1996; 371(1): 85.

[21] Gaykema RPA, Goehler LE, Armstrong CB, Khorsand J, Maier SF, Watkins LR. Differential FOS expression rat brain induced by lipopolisaccharide and staphylococcal enterotoxin B. Neuroimmunomodulation. 1999; 6: 220.

[22] Zhang Y-H, Lu J, Elmquist JK, Saper CB. Lipopolysaccharide activates specific populations of hypothalamic and brainstem neurons that project of the spinal cord. J. of Neuroscience. 2000; 20(17): 6578

[23] Perekrest SV, Gavrilov JV, Abramova TV, Novikova NS, Korneva EA. Activation of cells in hypothalamic structures after applicattion of antigens of the various nature (by c-fos gene expression). Medical immunology. 2006; 8(5-6): 631. [in Russian].

[24] Novikova NS, Perekrest SV, Kazakova TB, Rogers VJ, Korneva EA. Morphometric analysis of hypothalamic cells showing c-Fos proteins after movement restriction and EHFirradiation. Pathophysiology. 2008; 15: 19.

[25] Park S-M, Gaykema RPA, Goehler LE. How does immune challenge inhibit ingestion of palatable food? Evidence that systemic lipopolysaccharide treatment modulates key noda points of feeding neurocircuitry. Brain Behav. Immun. 2008; 22(8): 1160.

[26] Gaykema RP, Park SM, McKibbin CR, Goehler LE. Lipopolysaccharide suppresses activation of the tuberomammillary histaminergic system concomitant with behaviour: a novel target of immune-sensory pathways. Neuroscience. 2008; 152(1): 273

[27] Goehler LE, Gaykema RPA, Hansen K. Staphylococcal enterotoxin B induces fever, brain c-Fos expression, and serum corticosterone in rats. Am. J. Physiol. Regulatory Integrative Comp. Physiol. 2001; 280: R1434.

[28] Lacroix S, Rivest S. Functional circuitry in the brain of immune-challenged rats: Partial involvement of prostaglandins. J. Comp. Neurol. 1997; 387: 307.

[29] Brent EW, Ogimoto K, Tang J, Harris MK Jr., Raines EW, Schwartz MW. Evidence that LPS-induced anorexia depends upon central, rather than peripheral, inflammatory signals. Endocrinology. 2007; 148(11): 5230.

[30] Rothwell NJ, Hopkins SJ. Cytokines and the nervous system II. Actions and mechanisms of action. Trends Neurosci. 1995; 18: 130.

[31] Gaykema RPA, Daniels TE, Shapiro NJ, Thacker GC, Park S-M, Goehler LE. Immune chalenge and satiety-related activation of both distinct and overlapping neuronal populations in the brainstem indicate parallel pathways for viscerosensory signaling. Brain Res. 2009; 1294: 61.

[32] Bienkowski MS, Rinaman L. Noradrenergic inputs to the paraventricular hypothalamus contribute to hypothalamicpituitary-adrenal axis and central Fos activation in rats after acute systemic endotoxin exposure. Neurosci. 2008; 156(4): 1093

[33] Hollis JH, Lightman SL, Lowry CHA. Lipopolysaccharide has selective actions on sub-populations of catecholaminergic neurons involved in activation of the hypothalamic-pituitary-adrenal axis and inhibition of prolactin secretion. J. Endocrinology. 2005; 184: 393.

[34] Itoi K, Suda T, Tozawa F, Dobashi I, Ohmori N, Sakai Y, Abe K, Demura H. Microinjection of norepinephrine into the paraventricular nucleus of the hypothalamus stimulates corticotropin-releasing factor gene expression in conscious rats. Endocrinology. 1994; 135: 2177.

[35] Wan W, Wetmore L, Sorenson CM. Neural and biochemical mediators of toxin and stress-induced c-fos expression in the rat brain. Brain Res. Bull. 1994; 34: 7.

[36] Tkacs NC, Strack AM. Systemic endotoxin induces fos-like immunoreactivity in rat spinal sympathetic regions. J. of the autonomic nervous system. 1995; 51(1): 1.

[37] Tsagarakis S, Gillies G, Rees LH, Besser M, Grossman A. Interleukin-1 directly stimulates the release of corticotrophin releasing factor from rat hypothalamus. Neuroendocrinol. 1989; 49: 98.

[38] Weidenfeld J, Abramsky O, Ovadia H. Evidence for the involvement of the central adrenergic system in interleukin 1-induced adrenocortical response. Neuropharmacol. 1989; 28: 1411.

[39] Ovadia H, Abramsky OV, Conforti N, Saphier D, Weidenfeld $\mathrm{J}$. Effect of interleukin-1 on adrenocortical activitv in intact and hypothalamic deafferentated male rats. Exp. brain res. 1989; 76: 246.

[40] Matta S, Sineh I, Newton R, Sharo BM. The adrenocorticotropin response to interleukin-1 bela instilled into the rat median eminence depends on the local release of catecholamines. Endocrinol. 1990; 127: 2175.

[41] Chuluyan HE, Saphier D, Rohn WM, Dunn AJ. Noradrenergic innervation of the hypothalamus participates in adrenocortical responses to interleukin-1. Neuroendocrinol. 1992; 56: 106.

[42] Uribe RM, Lee S, Rivier C. Endotoxin stimulates nitric oxide production in the paraventricular nucleus of the hypothalamus through nitric oxide synthase I: Correlation with hypothalamic-pituitary-adrenal axis activation. Endocrinol. 1999; 140(12): 5971

[43] Rivest S, Laflamme N, Nappi RE. Immune challenge and immobilisation stress induce transcription of the gene encoding the CRF receptor in selective nuclei of the rat hypothalamus. J. of neurosci. 1994; 15(4): 2680.

[44] Lenczowski MJP, Bluthé R-M, Roth J, Rees GS, Rushforth DA, van Dam A-M, Tilders FJH, Dantzer R, Rothwell NJ, Luheshi GN. Central administration of rat IL-6 induces HPA activation and fever but not sickness behaviour in rats. Am J Physiol Regulatory Integrative Comp Physiol. 1999; 276: 652.

[45] Turnbull AV, Prehar S, Kennedy AR, Little RA, Hopkins SJ. Interleukin-6 is an afferent signal to the hypothalamopituitary-adrenal axis during local inflammation in mice. Endocrinology. 2003; 144(5): 1894

[46] Bethin KE, Vogt SK, Muglia LJ. Interleukin-6 is an essential, corticotrophin-releasing hormone-releasing hormone-independent stimulator of the adrenal axis during immune system activation. Bethin, K.E., Proc. Natl. Acad. Sci. USA. 2000; 97: 9317.

[47] Borges BC, Antunes-Rodrigues J, Castro M, Bittencourt JC, Elias CF, Elias LL. Expression of hypothalamic neuropeptides and the desensitisation of pituitary-adrenal axis and hypophagia in the endotoxin tolerance. Horm. Behav. 2007; 52(4): 508.

[48] Kaneko YS, Mori K, Nakashima A, Sawada M, Nagatsu I, Ota A. Peripheral injection of lipopolysaccharide enhances 
expression of inflammatory cytokines in murine locus coeruleus: possible role of increased norepinephrine turnover. J. Neurochem. 2005; 94(2): 393.

[49] Almeida MC, Steiner AA, Coimbra NC, Branco LGS. Thermoeffector neuronal pathways in fever: a study in rats showing a new role of the locus coeruleus. J. Physiol. 2004; 558(1): 283.

[50] Soriano RN, Ravanelli MIB, Batalhao ME, Branco LGS. Nitric oxide synthase inhibition into the rat locus coeruleus delays the LPS-induced fever. The FASEB Journal. 2008; 22: 1221.2 .

[51] Soriano RN, Ravanelli MI, Batalhao ME, Carnio EC, Branco LGS. Propyretic role of the locus coeruleus nitric oxide pathway. Exp. Physiol. 2010; 95: 669.

[52] Yilmaz MS, Myer BS, Feleder C, Millington WR. Blockade of $\alpha$-adrenergic receptors in the preoptic area/anterior hypothalamus prevents lipopolysaccharide evoked hypotension. The FASEB Journal. 2008; 22: 1227.8.

[53] Kopf BS, Langhans W, Geary N, Asarian L. Serotonin 2C receptor signalling in a diffuse neuronal network is necessary for LPS anorexia. Brain Res. 2010; 1306: 77.

[54] Swiergiel AH, Dunn AJ. Lack of evidence for a role of serotonin in interleukin-1-induced hypophagia. Pharmacol Biochem Behav. 2000; 65(3): 531.

[55] Hsieh PF, Chia LG, Ni DR, Cheng LJ, Ho YP, Tzeng $\mathrm{SF}$, Chang MH, Hong JS. Behavior, neurochemistry and histology after intranigral lipopolysaccharide injection. Neuroreport. 2002; 13(3): 277

[56] Nolan Y, Connor TJ, Kelly JP, Leonard BE. Lipopolysaccharide administration produces time-dependent and regionspecific alterations in tryptophan and tyrosine hydroxylase activities in rat brain. J Neural Transm. 2000; 107(12): 1393.

[57] Hunter RL, Cheng B, Choi DY, Liu M, Liu S, Cass WA, Bing G. Intrastriatal lipopolysaccharide injection induces parkinsonism in C57/B6 mice. J. Neurosci. Res. 2009; 87(8): 1913.

[58] Jung BD, Shin EJ, Nguyen XK, Jin CH, Bach JH, Park SJ, Nah SY, Wie MB, Bing G, Kim HC. Potentiation of methamphetamine neurotoxicity by intrastriatal lipopolysaccharide administration. Neurochem. Int. 2010; 56(2): 229.

[59] Bal-Price A, Brown GC. Inflammatory Neurodegeneration Mediated by Nitric Oxide from Activated Glia-Inhibiting Neuronal Respiration, Causing Glutamate Release and Excitotoxicity. J. Neurosci. 2001; 21(17): 6480.

[60] Mori K, Kaneko YS, Nakashima A, Fujiwara K, Nagatsu I, Ota A. Effect of peripheral lipopolysaccharide injection on dopamine content in murine anterior olfactory nucleus. J. Neural. Transm. 2003; 110(1): 31.

[61] Ota A, Mori K, Kaneko YS, Nakashima A, Nagatsu I, Nagatsu T. Peripheral lipopolysaccharide administration affects the olfactory dopamine system in mice. Ann. N. Y. Acad. Sci. 2008; 1148: 127.

[62] Kim YW, Kim KH, Ahn DK, Kim HS, Kim JY, Lee DC, Park SY. Time-course changes of hormones and cytokines by lipopolysaccharide and its relation with anorexia. J. Physiol. Sci. 2007; 57(3): 159.

[63] Reyes TM, Sawchenko PE. Involvement of the Arcuate Nucleus of the Hypothalamus inInterleukin-1-Induced Anorexia. The Journal of Neuroscience. 2002; 22(12): 5091.

[64] Painsipp E, Herzog H, Holzer P. Implication of neuropeptide-Y Y2 receptors in the effects of immune stress on emotional, locomotor and social behaviour of mice. Neuropharmacology. 2008; 55(1): 117.

[65] Palin K, Moreau ML, Sauvant J, Orcel H, Nadjar A, DuvoidGuillou A, Dudit J, Rabié A, Moos F. Interleukin-6 activates arginine vasopressin neurons in the supraoptic nucleus during immune challenge in rats. Am. J. Physiol. Endocrinol. Metab. 2009; 296: E1289.

[66] Grinevich V, Ma XM, Jirikowski G, Verbalis J, Aguilera G. Lipopolysaccharide endotoxin potentiates the effect of osmotic stimulation on vasopressin synthesis and secretion in the rat hypothalamus. J. Neuroendocrinol. 2003; 15(2): 141

[67] Xu S, Guo S, Jiang X, Yin Q, Umezawa T, Hisamitsu T Effect of indomethacin on the c-fos expression in AVP and $\mathrm{TH}$ neurons in rat brain induced by lipopolysaccharide. Brain. Res. 2003; 966(1): 13.

[68] Xu S, Guo S, Jiang X, Umezawa T, Hisamitsu T. The role of norepinephrine and nitric oxide in activities of rat argininevasopressin neurons in response to immune challenge. Neurosci. Lett. 2005; 383(3): 231.

[69] Matsunaga W, Miyata S, Takamata A, Bun H, Nakashima T, Kiyohara T. LPS-induced Fos expression in oxytocin and vasopressin neurons of the rat hypothalamus. Brain Res. 2000; 858(1): 9.

[70] Chiba S, Itateyama E, Oka K, Masaki T, Sakata T, Yoshimatsu H. Hypothalamic Neuronal Histamine Modulates Febrile Response but Not Anorexia Induced by Lipopolysaccharide. Experimental Biology and Medicine. 2005; 230(5): 334.

[71] Gaykema RPA, Park SM, McKibbin CR, Goehler LE. Lipopolysaccharide suppresses activation of the tuberomammillary histaminergic system concomitant with behaviour: a novel target of immune-sensory pathways. Neuroscience. 2008; 152(1): 273.

[72] Daniel RJ, O'Connor JC, Dantzer R, Freund GG. Inhibition of vagally mediated immune-to-brain signalling by vanadyl sulphate speeds recovery from sickness. PNAS. 2005; 102(42): 15184.

[73] Gaykema RPA, Goehler LE. Lipopolysaccharide challengeinduced suppression of Fos in hypothalamic orexin neurons: Their potential role in sickness behaviour. Brain, Behavior, and Immunity. 23: 2009; 926.

[74] Knigge U, Kjaer A, Jorgensen H, Garbarg M, Ross C, Rouleau A, Warberg J. Role of hypothalamic histaminergic neurons in mediation of ACTH and beta-endorphin responses to LPS endotoxin in vivo. Neuroendocrinology. 1994; 60(3): 243.

[75] Givalois L, Siaud P, Mekaouche M, Ixart G, Malaval F, Assenmacher I, Barbanel G. Involvement of central histamine in the early phase of ACTH and corticosterone responses to endotoxin in rats. Neuroendocrinology. 1996; 63(3): 219.

[76] Knigge U, Soe-Jensen P, Jorgensen H, Kjaer A, Moller M, Warberg J. Stress-induced release of anterior pituitary hormones: effect of $\mathrm{H} 3$ receptor-mediated inhibition of histaminergic activity or posterior hypothalamic lesion. Neuroendocrinology. 1999; 69(1): 44.

[77] Becskei C, Riediger H, Hernadfalvy DA, Lutz TA, Langhans W. Inhibitory effects of lipopolysaccharide on hypothalamic nuclei implicated in the control of food intake. Brain. Behav. Immun. 2008; 22(1): 56.

[78] Perekrest SV, Abramova TV, Novikova NS, Loskutov Yu V, Rogers VJ, Korneva EA. Changes in immunoreactivity of Orexin-A-Positive Neurons after an Intravenous Lipopolysaccharide injection. Medical Science Monitoring. 2008; 14(7): BR127.

[79] Phelps C, Chen L-T. Brain response to endotoxin. In: Phelps C, Korneva EA, editors. NeuroImmune Biology. Cytokines and the brain. Elsevier; 2008. p. 435. 
[80] Perekrest SV, Abramova TV, Novikova NS. Comparative analysis of the reaction of orexin-containing neurons in rat hypothalamus after injection of various doses of lipopolysaccharide. Russian Physiological Journal. 2009; 95(12): 1336. [in Russian].

[81] Bluthe RM, Walter P, Parnet CR, Laye S, Lestage J, Verrier D, Poole S, Stenning BE, Kelley KW, Dantzer R. Lipopolysaccharide induces sickness behaviour in rats by a vagal mediated mechanism. Acad. Sci III. 1994; 317: 499.

[82] Watkins LR, Wiertelak EP, Goehler LE, Mooney-Heiberger K, Martinez J, Furness L, Smith KP, Maier SF. Neurocircuitry of illness-induced hyperalgesia. Brain Res. 1994; 639: 283.

[83] Watkins LR, Goehler LE, Relton JK, Tartaglia N, Silbert L, Martin D, Maier SF. Blockade of interleukin-1-induced fever by subdiaphragmatic vagotomy; evidence for vagal mediation of immune brain communication. Neurosci. lett. 1995; 183: 27.

[84] Van Dam AM, Bol JG, Gaykema RPA, Goehler LE, Maier SF, Watkins LR, Tilders FJ. Vagotomy does not inhibit high dose lipopolysaccharide-induced interleukin1beta immunoreactivity in rat brain and pituitary gland Neurosci. Lett. 2000; 285(3): 169

[85] Layé S, Bluthe RM, Kent S, Combe C, Medina C, Parnet P, Kelley K, Dantzer R. Subdiaphragmatic vagotomy blocks induction of IL-1 beta mRNA in mice brain in response to peripheral LPS. Am. J. Physiol. 1995; 268: R1327.

[86] Hansen MK, Nguyen KT, Fleshner M, Goehler LE, Gaykema RPA, Maier SF, Watkins LR. Effects of vagotomy on serum endotoxin, cytokines, and corticosterone after intraperitoneal lipopolysaccharide. Am J Physiol Regulatory Integrative Comp Physiol. 2000; 278(2): R331.

[87] Schwartz GJ, Plata-Salaman CR, Langhans W. Subdiaphragmatic vagal deafferentation fails to block feedingsuppressive effects of LPS and IL-1 beta in rats. Am. J. Physiol. Regul. Integr. Comp. Physiol. 1997; 273(3): R1193.

[88] Fleshner M, Slibert L, Deaket T. TNF-alpha-induced corti costerone elevation but not serum protein or corticosteroid bind ng globulin reduction is vagally mediated. Brain res. bull. 1997; 44: 701.

[89] Fleshner M, Goehler LE, Hermann J, Relton JK, Maier SF, Watkins LR. Interleukin-1 beta induced corticosterone elevation and hypothalamic NE depletion is vagally mediated. Brain Res Bull. 1995; 37(6): 605.

[90] Kapcala LP, He JR, Gao Y. Subdiaphragmatic vagotomy inhibits intra-abdominal in terleukin-1b stimulation of adrenocorticotropin secretion. Brain Res. 1996; 728: 247.

[91] Azab AN, Kaplanski J. Vagotomy attenuates the effect of lipopolysaccharide on body temperature of rats in a dosedependent manner. Innate Immunity. 2001; 7(5): 359.

[92] Wieczorek M, Swiergiel AH, Pournajafi-Nazarloo H, Dunn AJ. Physiological and behavioral responses to interleukin1 beta and LPS in vagotomized mice. Physiol. Behav. 2005; 85(4): 500.

[93] Hermann GE, Emch GS, Tovar CA, Rogers RC. C-Fos generation in the dorsal vagal complex after systematic endotoxin is not dependent on the vagus nerve. Am. J. Physiol. Regulatory Integrative Comp. Physiol. 2001; 280: R289.

[94] Konsman JP, Luheshi GN, Bluthe RM, Dantzer R. The vagus nerve mediates behavioural depression, but not fever, in response to peripheral immune signals; a functional anatomical analysis. Eur. J. Neurosci. 2000; 12(12): 4434.

[95] Goehler LE, Erisir A, Gaykema RPA. Neural-immune interface in the rat area postrema. Neuroscience. 2006; 140(4): 1415.
[96] Ek M, Kurosawa M, Lundeberg T, Ericsson A. Activation of vagal afferents after intravenous injection of interleukin-1 $\beta$ : role of endogenous prostaglandins. J. neurosci. 1998; 18: 9471.

[97] Lu XY, Yang GZ, Sun HC. The activation of vagus afferent in response to lipopolysaccharide the role of interleukin-1. Sheng Li Xue Bao. 2002; 54(2): 111. [in Chinese].

[98] Hosoi T, Okuma Y, Matsuda T, Nomura Y. Novel pathway for LPS-induced afferent vagus nerve activation: possible role of nodose ganglion. Auton. Neurosci. 2005; 120(1-2): 104.

[99] Goehler LE, Gaykema PR, Hammach SE, Maier SF, Watkins LR. Interleukin-1 induces c-Fos immunoreactivity inprimary afferent neurons of the vagus nerve. Brain Res. 1998; 804: 306.

[100] Gaykema RPA, Goehler LE, Bol FJH, McGorry MM, Maier SF, Watkins LR. Bacterial endotoxin induces Fos immunoreactivity in primary afferent neurons of the vagus nerve. Neuroimmunomodulation. 1998; 5: 234.

[101] Elmquist JK, Ackermann MR, Register KB, Rimler RB, Ross LR, Jacobson CD. Induction of Fos-like immunoreactivity in the rat brain following Pasteurella multocida endotoxin administration. Endocrinology. 1993; 133: 3054.

[102] Elmquist JK, Saper CB. Activation of neurons projecting to the paraventricular hypothalamic nucleus by intravenous lipopolysaccharide. J. of Comp.neurol. 1996; 374(3): 315.

[103] Sagar SM, Price KJ, Kasting NW, Sharp FR. Anatomic patterns of Fos immunostaining in rat-brain following systemic endotoxin administration. Brain res. bul. 1995; 36(4): 381.

[104] Day HE, Akil H. Differential pattern of c-fos mRNA in rat brain following central and systemic administration of interleukin-1-beta: implications for mechanism of action. Neuroendocrinology. 1996; 63(3): 207.

[105] Gaykema RP, Balachandran MK, Godbout JP, Johnson RW, Goehler LE. Enhanced neuronal activation in central autonomic network nuclei in aged mice following acute peripheral immune challenge. Auton Neurosci. 2007; 131(1-2): 137.

[106] Ge X, Yang Z, Duan L, Rao Z. Evidence for involvement of the neural pathway containing the peripheral vagus nerve, medullary visceral zone and central amygdaloid nucleus in neuroimmunomodulation. Brain Res. 2001; 914(1-2): 149.

[107] Marvel FA, Chen CC, Badr N, Gaykema RPA, Goehler LE. Reversible inactivation of the dorsal vagal complex blocks lipopolysaccharide-induced social withdrawal and cFos expression in central autonomic nuclei. Brain Behav. Immun. 2004; 18(2): 123.

[108] Gaykema RPA, Goehler LE, Lyte M. Brain response to cecal infection with Campylobacter jejuni: analysis with Fos immunohistochemistry. Brain Behav. Immun. 2004; 18(3): 238.

[109] Goehler LE, Gaykema RPA, Opitz N, Reddaway R, Badr $\mathrm{N}$, Lyte M. Activation in vagal afferents and central autonomic pathways: early responses to intestinal infection with Campylobacter jejuni. Brain Behav. Immun. 2005; 19(4): 334.

[110] Goehler LE, Park S-M, Opitz N, Lyte M, Gaykema RPA. Campylobacter jejuni infection increases anxiety-like behaviour in the holeboard: possible anatomical substrates for viscerosensory modulation of exploratory behaviour. Brain Behav. Immun. 2008; 22(3): 354. 